Revista Mídia e Cotidiano

ISSN: 2178-602X

Artigo Seção Livre

Volume 14, Número 1, jan-abr de 2020

Submetido em: 13/10/2019

Aprovado em: 11/02/2020

\title{
O movimento antivacina no YouTube nos tempos de pós-verdade: Educação em saúde ou desinformação?
}

\section{Anti-vaccine movement in YouTube at post true times: Health education or disinformation?}

\author{
Bianca Barros da COSTA ${ }^{1}$ \\ Daiane de Jesus VIEGAS ${ }^{2}$ \\ Thamyris Almeida MOREIRA ${ }^{3}$ \\ Paula Alvarez ABREU ${ }^{4}$
}

\section{Resumo}

Apesar dos benefícios da vacinação, movimentos antivacinação têm se espalhado pelo mundo. Neste estudo foi feita uma análise dos vídeos sobre o movimento antivacina no YouTube, o seu impacto em visualizações e a aceitação dos usuários. Foram realizadas duas buscas em períodos diferentes e 14 vídeos se mantiveram entre os mais relevantes nas buscas. A maioria dos vídeos foi contra o movimento e nestes havia profissionais de saúde que explicaram os benefícios das vacinas, enquanto os vídeos a favor usaram argumentos sem base científica, fake news e teorias conspiratórias. Apesar de serem a minoria, os vídeos a favor do movimento tiveram milhares de visualizações e houve aumento da razão like/dislike, mostrando que muitos seguidores se identificaram com o

\footnotetext{
${ }^{1}$ Possui Graduação em Farmácia pela Universidade Federal do Rio de Janeiro - campus Macaé. Mestrado em Produtos Bioativos e Biociências pela Universidade Federal do Rio de Janeiro. Atualmente é aluna de doutorado na UFRJ/Macaé. E-mail: costa.biancab@gmail.com. ORCID: 0000-0001-8962-2639.

${ }^{2}$ Bióloga formada pela Unesp. Mestra na área de Microbiologia e Imunologia no programa de Pósgraduação em Biopatologia Bucal. Doutorado pelo Programa de Pós-graduação em Produtos Bioativos e Biociências na UFRJ, pesquisando moléculas sintéticas com atividades antifúngica e antiviral. Realizou parte de sua pesquisa na Universidade da Flórida, EUA, com bolsa PDSE da Capes. Atualmente, trabalha em seu pós-doutorado pesquisando moléculas com atividade antifúngica sobre Sporothrix sp., projeto financiado pelo CNPq. E-mail: daianej1 @ gmail.com. ORCID: 0000-0002-4829-6395.

${ }^{3}$ Graduada em Farmácia pela Universidade Federal do Rio de Janeiro, no ano de 2013. Mestrado pela UFRJ em 2015 no Programa de Pós-graduação em Produtos Bioativos e Biociências (PPG- PRODBIO). Doutoranda pelo PPG - PRODIO da UFRJ-campus Macaé e atualmente professora da Faculdade Salesiana Maria Auxiliadora desde 2015 e da Fundação Educacional da Região dos lagos, desde 2018. Email: thamyris.pharma@gmail.com. ORCID: 0000-0003-3718-7131.

${ }^{4}$ Professora adjunta III da Universidade Federal do Rio de Janeiro. Doutora em Neurociências pela Universidade Federal Fluminense. Mestrado em Neuroimunologia na mesma instituição. Possui graduação em Farmácia Industrial pela UFF. Atualmente é membro permanente do Programa de Pósgraduação em Produtos Bioativos e Biociências da UFRJ. E-mail: abreu_pa@yahoo.com.br. ORCID: 0000-0003-2204-3012.
} 


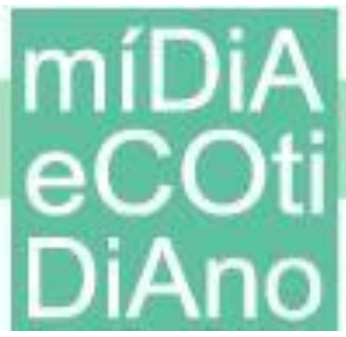

conteúdo. Em tempos de pós-verdade é essencial entender como as mídias sociais influenciam nas decisões em saúde.

Palavras-chave: Antivacinação. YouTube. Vídeos. Saúde. Fake News.

\begin{abstract}
Despite the benefits of vaccination, the anti-vaccination movement has spread around the world. In this study, we analyzed the videos about the anti-vaccine movement from YouTube, its impact on views and user acceptance. Two searches were performed at different times and 14 videos remained among the most relevant in the searches. Most of the videos were against the movement and in these, there were health professionals who explained the benefits of vaccines, while the videos in favor used unscientific arguments, fake news and conspiracy theories. Despite being a minority, the videos in favor had thousands of views and the like / dislike ratio increased, showing that many followers identified with the content. In post-truth times it is essential to understand how social media influence health decisions.
\end{abstract}

Keywords: Antivaccination. YouTube. Videos. Health. Fake News.

\title{
Introdução
}

O movimento antivacina engloba uma corrente de pensamento em que as pessoas optam por não se vacinar ou a seus filhos, baseando-se em supostos efeitos colaterais advindos da imunização (VASCONCELLOS-SILVA et al., 2015; MIZUTA et al., 2018). Este movimento iniciou-se em 1998 após a publicação de um artigo no periódico inglês The Lancet, em que o médico Dr. Andrew Wakefield e colaboradores afirmavam a relação direta entre o autismo e a vacina tríplice viral (DOBSON, 2003; DYER, 2008). Um tempo depois, o General Medical Council inglês publicou um relatório descrevendo a atitude antiética e irresponsável dos autores, assim Wakefield foi criminalmente responsabilizado, teve o registro médico cassado e o artigo foi retirado dos arquivos do periódico (DOBSON, 2003). Mesmo mediante a revelação da fraude e da falta de evidências científicas da correlação entre o autismo e a vacinação, foi notória a redução da procura pela vacinação, principalmente por adultos, em algumas partes do mundo pelo medo do desenvolvimento do autismo e de efeitos adversos graves associados aos componentes presentes nas formulações das vacinas, dando força ao movimento antivacina (GUIMAR ÃES, 2017). 
Atualmente, não se fala mais tanto sobre a questão do autismo relacionado à vacinação, porém os grupos que se mostram adeptos ao movimento falam da presença de substâncias potencialmente tóxicas nas formulações das vacinas e os efeitos adversos, e também do apelo comercial das indústrias (DOBSON, 2003; DYER, 2008; VASCONCELLOS-SILVA et al., 2015; WANG; BARAS, 2015; GUIMARÃES, 2017; MIZUTA et al., 2018).

As vacinas são consideradas as ferramentas mais eficazes para a prevenção de diversas doenças, reduzindo a mortalidade infantil e economizando bilhões de dólares em custos com saúde a cada ano (CDC, 2011; SIQUEIRA et al., 2017). Ações planejadas, desenvolvidas no Brasil, como as campanhas de imunização, contribuíram para a erradicação da varíola em 1973 e da poliomielite em 1998, assim como auxiliam no controle do tétano, formas graves de tuberculose, difteria, coqueluche, caxumba, rubéola, hepatite B e influenza (FEIJÓ; SÁFADI, 2006). Em 2016, o Brasil recebeu da OMS o registro de erradicação do sarampo. Entretanto, nos últimos anos, ocorreram surtos da doença devido à redução na cobertura vacinal (BBC NEWS, 2018). Em todo o mundo os casos notificados da doença aumentaram em $30 \%$ a partir de 2016, enquanto a cobertura global com a primeira dose da vacina está em $85 \%$ na primeira dose e $67 \%$ na segunda, o que é menor do que os $95 \%$ desejáveis para evitar os surtos (OPAS, 2018).

Devido à popularização e difusão das informações acessadas via internet, há maior facilidade na transmissão de determinadas crenças. Muitas pessoas pesquisam online sobre saúde e a informação encontrada impacta na formação de opinião e tomada de decisão (KATA, 2012). Na internet, os indivíduos formadores de opinião são conhecidos como influenciadores digitais e são capazes de formar redes, reunir seguidores, selecionar conteúdos para influenciar estes seguidores e atuar também no marketing de produtos (KUMAR; GRUPTA, 2016; ALMEIDA et al., 2018). Segundo Bauman (2001), as referências de líderes não existem mais e as pessoas buscam a figura do conselheiro, que são pessoas que não precisam ser autoridades na área, mas que agem como exemplos a serem seguidos e, como as pessoas perderam outras referências, seguem a procurar novas orientações, novos exemplos e novos conselhos para suas vidas. Os influenciadores digitais são exemplos destes conselheiros, e alguns estão no YouTube influenciando as pessoas a partir do relato de suas vidas. 
As plataformas digitais como o YouTube são tidas como ferramentas para obtenção de conhecimento, com ou sem referência científica que comprove (KATA, 2012). Estudos mostram que cerca de $80 \%$ dos usuários da Internet pesquisam informações sobre saúde online (FOX, 2011). As estatísticas mais recentes mostram que $16 \%$ dos buscadores pesquisados on-line são para informações sobre imunização ou vacinação e, deste grupo, $70 \%$ dizem que os resultados encontrados influenciaram as decisões de tratamento. Além disso, pesquisas demonstraram que a Internet, atualmente, aparece disputando com médicos como a principal fonte de aconselhamento em saúde (VASCONCELLOS-SILVA et al., 2015; SARASOHN-KAHN, 2008).

A utilização de informações em saúde obtidas na internet é uma questão de saúde pública complexa e que merece atenção da sociedade como um todo, tendo em vista os potenciais efeitos e riscos relacionados ao uso destas informações (MORETTI et al., 2012). A facilidade no acesso e velocidade do tráfego de informações com a internet tem facilitado o consumo e disseminação de informações falsas e termos como fake news, pós-verdade e desinformação se tornaram populares. Nesta nova relação com o saber na sociedade pósmoderna ocorre ascensão da desconfiança em relação à história oficial, e a sobrecarga cognitiva com o excesso de informação leva a uma condição de apatia denominada por alguns autores de "zumbificação da informação" em que as pessoas consomem e disseminam informações falsas ou distorcidas sem notar. Isso ocorre por vezes por falta de uma análise crítica e checagem das fontes (LEITE; MATOS, 2017; LYOTARD, 2014). Sendo assim, esse estudo tem como objetivo avaliar os vídeos publicados na plataforma digital do YouTube que estejam relacionados com o movimento antivacina, investigando a opinião apresentada nos vídeos e a potencial influência destes de acordo com as visualizações e aceitação dos usuários.

\section{Métodos}

A pesquisa do tipo descritiva observacional, com abordagem quali-quantitativa, foi realizada na plataforma digital de compartilhamento de vídeos YouTube (www.youtube.com) em duas etapas; a primeira coleta foi realizada no dia 29 de maio de 2018 e, tendo em vista que a relevância dos vídeos em plataformas como o YouTube pode mudar com o passar do tempo, foi realizada uma segunda coleta no dia 23 de agosto de 
2019 a fim de analisar como este assunto está sendo abordado e se houve uma tendência para algum dos posicionamentos contra ou a favor do movimento nos vídeos, bem como verificar a permanência dos vídeos identificados na primeira etapa entre os mais relevantes.

As palavras-chave, usadas separadamente para identificar os vídeos em português relacionados ao movimento antivacina, foram "movimento antivacina" e "antivacinação". Foram incluídos os vídeos em português que faziam referência direta ao movimento antivacina, usando como base o próprio discurso de cada um. Foram excluídos vídeos duplicados, em outros idiomas, sobre doenças ou assuntos não relacionados, sobre vacinas específicas ou campanhas de vacinação e os vídeos de cunho religioso sem opinião sobre o assunto (Figura 1).

\section{Figura 1 - Fluxograma utilizado para a seleção dos vídeos a serem analisados}

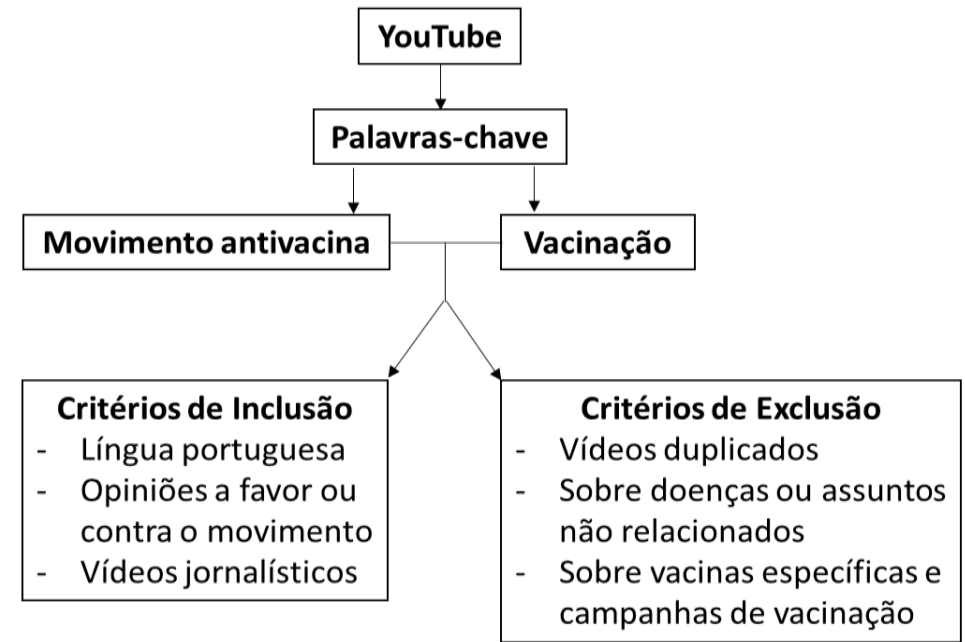

Fonte: Elaborado pelas autoras.

Dessa forma, os vídeos foram categorizados em três grupos: aqueles que apresentaram opinião direta a favor, os vídeos contra o movimento antivacina e vídeos jornalísticos sem opinião direta, sendo estes considerados neutros; e foi realizada a identificação em relação à área de atuação profissional do responsável pelo canal que publicou o vídeo. Além disso, foram obtidas as seguintes informações de cada vídeo selecionado: duração do vídeo, tempo na plataforma desde o dia de postagem até o dia de análise, número de visualizações, número de curtidas (like) e não curtidas (dislike). É importante salientar que o tempo do vídeo na plataforma, do dia de postagem até a data da análise foi considerado para os cálculos das visualizações por dia. Em cada grupo, os 


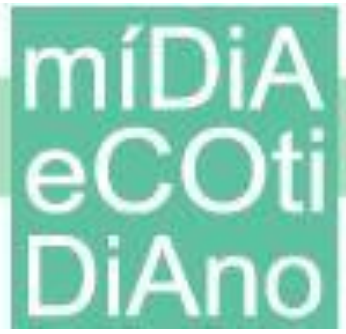

valores de visualizações, curtidas (like) e não curtidas (dislike) foram somados e divididos pelo número de vídeos, possibilitando desta forma uma comparação entre os diferentes grupos.

\section{Resultados}

Primeira etapa de análise dos vídeos do YouTube (29/05/2018)

Usando as palavras-chaves "movimento antivacina" foram encontrados 165 vídeos e com "antivacinação" foram encontrados 319, totalizando uma amostra de 484 vídeos para avaliação sobre o tema. Destes vídeos, 426 foram descartados após a aplicação dos critérios de exclusão, restando 59 vídeos elegíveis para a avaliação. A grande maioria dos vídeos foi descartada por tratarem de relatos sobre vacinas específicas como febre amarela e HPV, entre outras, e não ao movimento antivacina em si. Após a categorização dos vídeos nos grupos neutro, a favor ou contra o movimento antivacina, foi possível observar uma maior quantidade de vídeos no grupo contra o movimento (37) representando aproximadamente $62 \%$ do total, em comparação com o grupo a favor (11) e neutro (11). No grupo de vídeos contra o movimento foi observada maior aceitação quando avaliada a razão like/dislike (81) e de visualizações por dia (40) (Tabela 1).

Tabela 1 - Características dos vídeos dentro dos grupos analisados (A favor, Contra e Neutro) na primeira etapa da pesquisa, realizada em maio de 2018

\begin{tabular}{lcccccccc}
\hline Grupos & $\mathbf{N}$ & $\boldsymbol{\%}$ & $\begin{array}{c}\text { Visuali- } \\
\text { zação }\end{array}$ & $\begin{array}{c}\text { Dias no } \\
\text { ar }\end{array}$ & $\begin{array}{c}\text { Visuali- } \\
\text { zação/dia }\end{array}$ & Like & Dislike & $\begin{array}{c}\text { Like/ } \\
\text { Dislike }\end{array}$ \\
\hline A favor & 11 & 18 & 8858 & 564 & 15 & 2346 & 181 & 13 \\
Contra & 37 & 62 & 687601 & 17374 & 40 & 70612 & 869 & 81 \\
Neutro & 11 & 19 & 1722 & 432 & 4 & 820 & 17 & 48 \\
\hline
\end{tabular}

Fonte: Elaborado pelas autoras.

Destaca-se neste grupo o canal "Nerdologia" com 485.420 visualizações do seu vídeo, o que é justificado pelo fato deste canal ser relativamente bem conhecido no meio digital por voltar seus conteúdos para a divulgação científica, podendo, desta forma, ter grande influência sobre os seus mais de dois milhões de seguidores (FOX, 2011). Quando este vídeo foi retirado dos cálculos, o grupo contra o movimento passou a apresentar uma 


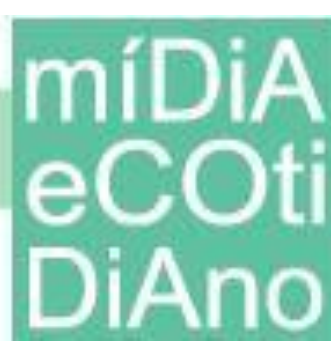

razão de like/dislike igual a 41,4 e visualizações/dia igual a 13, o que foi menor do que a média de visualização/dia no grupo a favor. Assim, claramente é observada a elevação dos valores dentro deste grupo por causa do referido vídeo. De modo semelhante, no grupo a favor do movimento antivacina foi observado o canal "Capixaba otário" com 52.114 visualizações, e quando retirado dos cálculos, a razão de visualizações/dia caiu de 16 para 10, não mostrando, no entanto, alterações na relação like/dislike, mostrando assim como um único vídeo postado pode ter influência para formar opinião, seja esta influência positiva ou negativa. Este fato não foi observado no grupo neutro.

Quando foram avaliadas as áreas de atuação profissional dos responsáveis pelas postagens dos vídeos, dentro dos grupos previamente categorizados (Figura 2), foi possível observar que dos 11 vídeos analisados no grupo a favor do movimento antivacina, um era de profissional da saúde, sendo um médico que se apresentava como inserido na medicina tradicional e alternativa, enquanto que os outros 10 vídeos eram de canais onde não havia especificação da formação ou área de atuação. Também não houve relato de opinião de outros profissionais da área da saúde em nenhum destes 10 vídeos.

\section{Figura 2 - Área de formação dos responsáveis pelos vídeos nos grupos estudados na primeira análise}

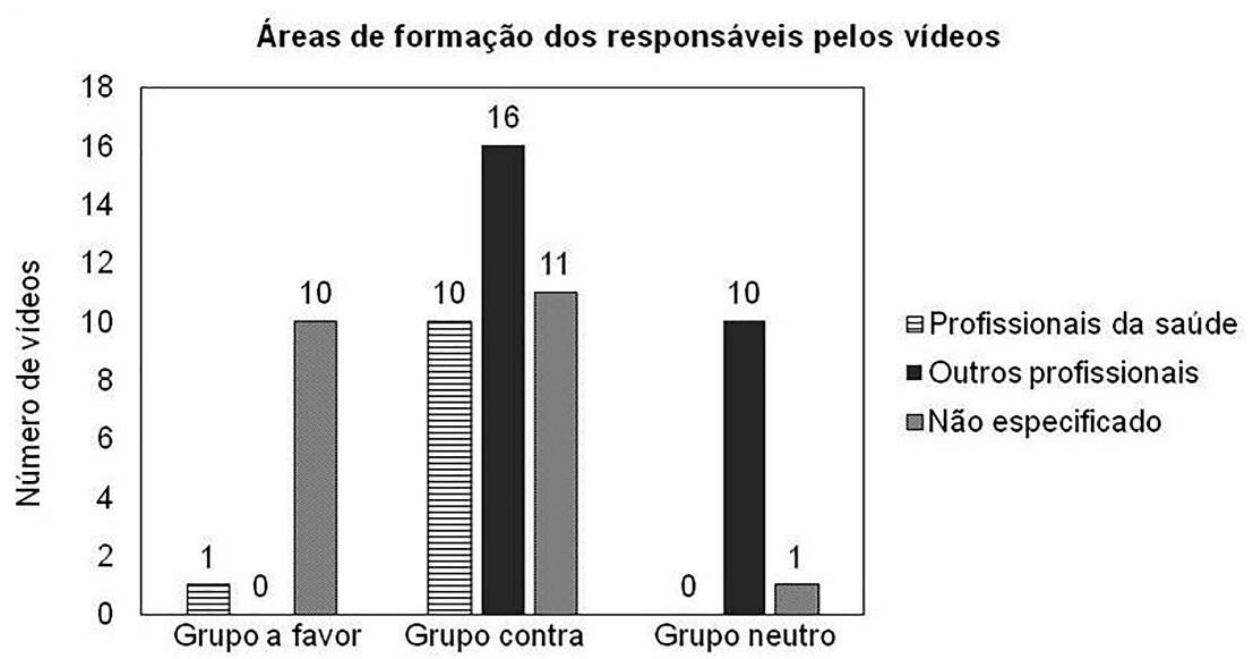

Fonte: Elaborado pelas autoras.

No grupo contra o movimento antivacina, dos 37 vídeos postados, 10 vídeos eram pertencentes a profissionais da saúde (médicos em sua grande maioria), em 11 vídeos não havia especificação da formação ou área de atuação do responsável e 16 eram 


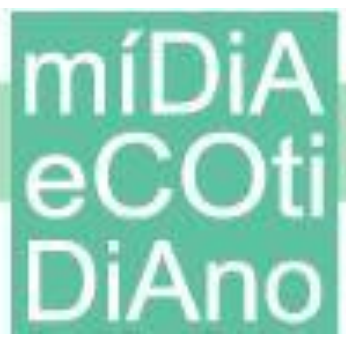

profissionais de outras áreas, sendo, neste último, 14 vídeos jornalísticos que mostravam opinião direta. Neste caso é interessante destacar o papel dos profissionais de saúde comprometidos em mostrar a opinião contra o movimento, tendo em vista o risco à saúde que representa a não imunização; e, também, dos vídeos jornalísticos que, em muitos casos, se mantém neutros em reportagens que dividem a opinião pública, mas que nestes vídeos também colocaram claramente a opinião contra o movimento. Já no grupo neutro, dos 11 vídeos publicados, 10 eram jornalísticos mostrando reportagens com relatos de pessoas a favor e contra o movimento antivacina, sem opinar de forma direta, enquanto no outro vídeo a área de atuação do responsável não foi especificada. Não foram encontrados vídeos publicados por profissionais da saúde que se enquadrassem neste grupo.

Conforme a análise dos 59 vídeos selecionados, pudemos perceber um crescente aumento da quantidade de vídeos publicados com o passar dos anos, sendo o mais antigo postado no ano de 2013. O ano de 2017 foi o que apresentou um maior número de vídeos, somando um total de 33 vídeos, enquanto em 2018 (até maio) foram postados 10. Também foi possível observar que os vídeos contra o movimento cresceram em proporção maior que dos vídeos a favor (Figura 2).

\section{Segunda etapa de análise dos vídeos do YouTube (23/08/2019)}

No segundo levantamento, utilizando os mesmos parâmetros da primeira etapa foram identificados, novamente, 59 vídeos mais relevantes sobre o tema, com a permanência de 14 vídeos selecionados no primeiro levantamento, o que corresponde a $23 \%$. A porcentagem de vídeos recentes sobre o tema (77\%) evidencia que este assunto está sendo intensamente debatido na sociedade. Neste novo levantamento, os vídeos contra o movimento antivacinação somaram 44, o que representa $75 \%$ dos vídeos, número maior que a pesquisa anterior. Os vídeos neutros somaram 10, sendo que 7 deles já tinham sido selecionados na etapa anterior. Por último, foram 5 vídeos a favor do movimento, um número bem menor que encontrado na primeira etapa (Tabela 2). 
Tabela 2 - Características dos vídeos dentro dos grupos analisados (A favor, Contra e Neutro) na segunda etapa da pesquisa, realizada em agosto de 2019

\begin{tabular}{ccccccccc}
\hline Grupos & N & $\%$ & $\begin{array}{c}\text { Visuali- } \\
\text { zação }\end{array}$ & $\begin{array}{c}\text { Dias no } \\
\text { ar }\end{array}$ & $\begin{array}{c}\text { Visuali- } \\
\text { zação/dia }\end{array}$ & Like & Dislike & $\begin{array}{c}\text { Like/ } \\
\text { Dislike }\end{array}$ \\
\hline A favor & 5 & 8 & 5301 & 158 & 34 & 978 & 20 & 49 \\
Contra & 44 & 75 & 44503 & 289 & 154 & 7335 & 101 & 73 \\
Neutro & 10 & 17 & 11980 & 643 & 19 & 275 & 25 & 11 \\
\hline
\end{tabular}

Fonte: Elaborado pelas autoras.

Nesta segunda análise, portanto, verificou-se uma tendência para a produção de vídeos contra o movimento, com redução dos vídeos a favor, entre os mais relevantes. Observa-se, também, que aumentou a visualização por dia nos 3 grupos. Apesar da razão like/deslike ter se mantido maior no grupo contra, em relação aos outros, ela aumentou no grupo "A favor" e reduziu no grupo "Neutro" e "Contra".

Em relação ao perfil profissional, no grupo "A favor" há somente um vídeo: "Urgente! Não tomem vacinas", do Canal Variedades, cuja descrição refere-se à pessoa que fala no vídeo como "um médico conceituado", contudo, não há o nome do profissional e nem sua especialidade médica. Neste vídeo, o suposto médico (um senhor aparentemente mais velho, próximo da meia-idade), que estava vestido de branco, embora sem avental, diz que a vacina pode ser um perigo e a relaciona com uma "Nova ordem mundial" que quer reduzir a população com um genocídio. Ele usa frases impactantes e termos populares e incorretos como "Vacinas são venenos que entram no corpo", ou "Vírus do câncer" e ainda "Fungo do câncer".

Ao pesquisar a fonte do vídeo, nota-se que se trata, na verdade, de uma postagem de um vídeo vinculado a um canal maior: Med Natural, com 484 mil inscritos. Neste canal, o vídeo teve mais de 1 milhão de visualizações, com 58 mil curtidas. Este mesmo canal tem como responsável o suposto médico referido no Canal Variedades. Entretanto ele não se define médico e em seus vídeos há apenas seu nome. Além do canal do YouTube mencionado, ele ainda possui outro canal com o seu nome, com mais de 124 mil inscritos, onde posta basicamente os mesmos vídeos e também tem um site, no qual se apresenta como terapeuta holístico e que se dedica a técnicas alternativas para a saúde. 


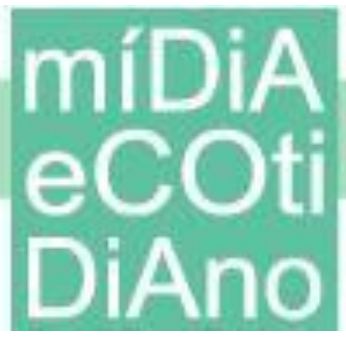

Entre os vídeos do grupo "Contra", 19 apresentam profissionais da saúde, todos eles com os nomes e formação mencionados. O vídeo mais visualizado desta categoria: "Vacinas fazem mal? Nostalgia Ciência" não é apresentado por um profissional da saúde, mas por um Youtuber famoso entre os jovens, Felipe Castanhari, que produz vídeos descontraídos com assuntos diversos de interesse deste público. Seu canal possui a playlist "Nostalgia Ciência" que, além da vacina, aborda temas como a origem do universo e a extinção dos dinossauros. O Youtuber possui uma linguagem acessível a crianças e adolescentes e seus vídeos possuem animações divertidas que muito provavelmente os atraem. Nota-se que, embora seja um vídeo voltado para o entretenimento, há a preocupação de trazer conteúdo informativo de qualidade. Esta proposta parece eficiente para despertar o interesse dos jovens para questões de ciências e saúde, uma vez que este vídeo teve mais de um milhão de visualizações.

No grupo "Neutro", como são canais, em sua maioria, que reproduzem reportagens, são apresentados por jornalistas ou outros profissionais que trazem notícias ou mostram opiniões diversas sobre o tema (Figura 3). Nesta categoria, o vídeo de maior impacto, de acordo com o número de visualizações por dia, é uma reportagem do programa televisivo Domingo Espetacular, transmitido pela Rede Record. Este vídeo tem caráter informativo com linguagem simples e de fácil compreensão e suscita a discussão sobre a possibilidade de não vacinar as crianças. Nesta reportagem, a jornalista menciona a obrigatoriedade de os pais vacinarem seus filhos de acordo com o calendário do Ministério da Saúde, segundo as leis brasileiras. Prosseguindo, o vídeo mostra uma mãe que vacina assiduamente seu filho e que considera a vacinação de extrema importância para a saúde do filho e uma outra mãe, a qual não quis se identificar, que decidiu não vacinar seus filhos e buscou outras alternativas, como a homeopatia.

O vídeo ainda mostra argumentos a favor da vacinação defendidos por médicos experientes e renomados, sendo um deles o vice-presidente da Sociedade Brasileira de Pediatria, Dr. Clóvis Francisco Constantino, o qual se apresenta vestido de terno e gravata, o que confere maior seriedade ao seu discurso. Para defender os argumentos contra a vacinação, entrevistaram uma ativista inglesa, Magda Taylor, e uma jornalista que teve alergia a várias vacinas e por isso não vacina seus filhos e é adepta de alternativas como a medicina chinesa, homeopatia e florais. Embora a reportagem apresente opiniões 


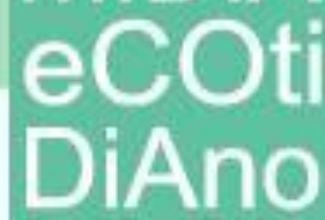

diferentes acerca da vacina, há a tendência de mostrar a importância da vacinação. Esta característica é comum entre os vídeos do grupo neutro.

Figura 3 - Área de formação dos responsáveis pelos vídeos nos grupos: a favor, neutro e contra o movimento antivacina

Áreas de formação dos responsáveis pelos vídeos

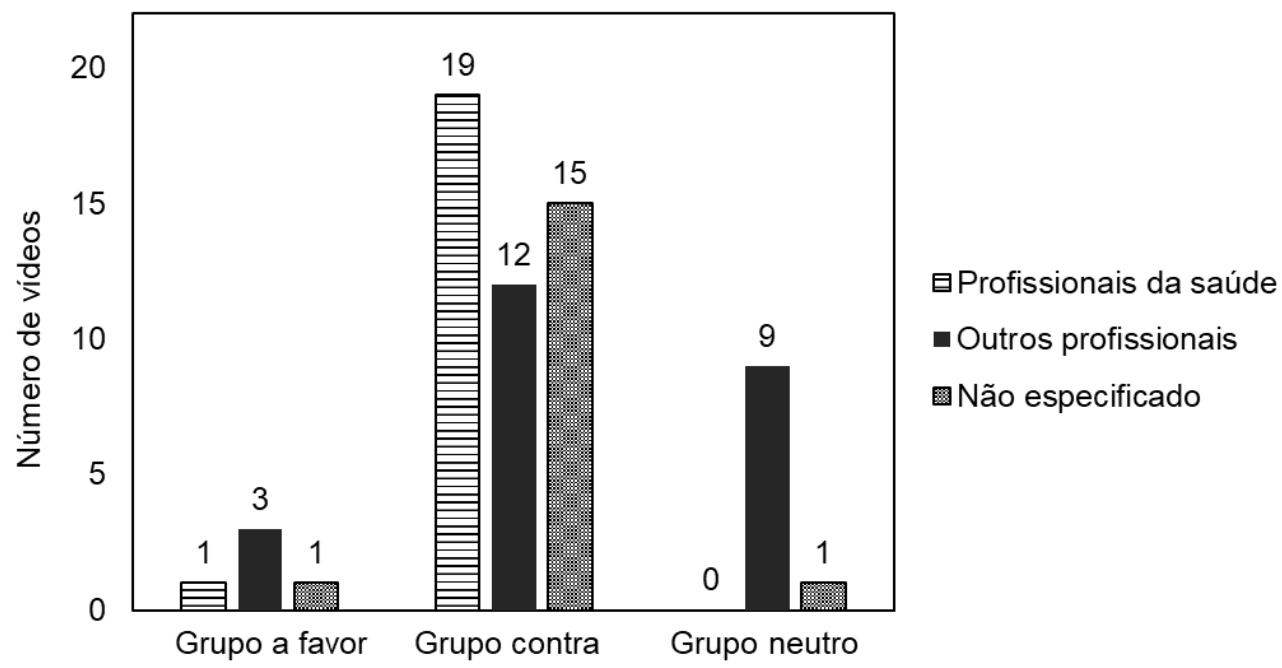

Fonte: Elaborado pelas autoras.

Neste segundo levantamento, a maioria dos vídeos mais relevantes foi recente, sendo 30 vídeos de 2019 e 19 vídeos de 2018 mostrando que é um tema que está em alta e sendo divulgado recentemente. Os vídeos que permaneceram como os mais relevantes ("Contra" e "Neutro") e os vídeos recentes "A favor" do movimento mostram alguns pontos em comum entre eles em relação ao conteúdo e forma de abordagem (Quadro 1).

Quadro 1 - Similaridades encontradas entre os vídeos nos grupos Contra, Neutro e A favor do movimento antivacina e duração dos vídeos em cada grupo

\begin{tabular}{|c|c|c|}
\hline & Descrição & $\begin{array}{l}\text { Duração dos } \\
\text { vídeos }\end{array}$ \\
\hline Contra & $\begin{array}{l}\text { - Explicação de um profissional na área de saúde } \\
\text { - Explica os benefícios das vacinas } \\
\text { - Aborda o histórico, consequências e malefícios deste } \\
\text { movimento }\end{array}$ & $\begin{array}{l}\text { Máxima = 1:00:00 } \\
\text { Mínima = 00:01:30 } \\
\text { Média }=00: 13: 20\end{array}$ \\
\hline Neutro & $\begin{array}{l}\text { - Introdução do tema geralmente feita por um jornalista } \\
\text { ou apresentador } \\
\text { - Entrevista com especialistas que defendem a vacinação } \\
\text { - Mostram os motivos que levam pessoas a serem contra } \\
\text { a vacinação }\end{array}$ & $\begin{array}{l}\text { Máxima }=00: 25: 19 \\
\text { Mínima }=00: 00: 40 \\
\text { Média }=00: 15: 03\end{array}$ \\
\hline
\end{tabular}




\begin{tabular}{|c|c|c|}
\hline A favor & $\begin{array}{l}\text { - Usam argumentos sem base científica e "fake news" } \\
\text { - Baseiam-se em casos isolados para justificarem a sua } \\
\text { posição. } \\
\text { - Falam sobre teorias conspiratórias como esterilização } \\
\text { em massa e redução populacional para justificarem o } \\
\text { movimento }\end{array}$ & $\begin{array}{l}\text { Máxima }= \\
00: 17: 34 \\
\text { Mínima = 00:02:04 } \\
\text { Média = 00:09:49 }\end{array}$ \\
\hline
\end{tabular}

Fonte: Elaborado pelas autoras.

A duração média dos vídeos foi de 9 minutos e 49 segundos no grupo "A favor"; 15 minutos e 3 segundos no grupo "Neutro"; e 13 minutos e 20 segundos no grupo contra. Nota-se que há a tendência de os vídeos "A favor" serem mais curtos, o que facilita ter mais visualizações. Em todos os grupos, os vídeos de maior destaque não ultrapassaram 20 minutos.

De modo geral, os vídeos “A favor" são apresentados de maneira informal, sem muita elaboração e edição e tampouco trazem dados confiáveis organizados em gráficos ou tabelas. Nestes vídeos foram identificadas fake news por meio de características como a utilização de afirmações sensacionalistas como dizer que nas vacinas há agentes esterilizantes ou que a nova ordem mundial quer reduzir a população promovendo genocídio. Estes vídeos se utilizam de uma linguagem popular, como no vídeo com maior visualização por dia nesta categoria que é o "Antivacina na Conversa com Bial, porque a Globo quer que você se vacine? Movimento antivacina”, no qual há apenas a voz do apresentador e imagens de um episódio do programa televisivo mencionado. Neste vídeo o narrador menciona, sem citar nenhum estudo ou exemplo, o poder de cura de plantas medicinais, induzindo as pessoas a acreditarem que estas possam ser uma alternativa às vacinas.

Uma exceção dentro deste grupo é o vídeo "Não Vacine Seus Filhos!” do canal Elder vip, o qual é estruturado no formato de uma reportagem e apresenta casos de trombose venosa causada supostamente pela vacina HPV. O vídeo mostra a opinião de um médico neurocirurgião paramentado, cujo nome completo foi mostrado no vídeo e que acredita na relação da doença com a administração da vacina. Além disso, no vídeo menciona-se uma ação do Ministério Público Federal (MPF) que pede a proibição da vacina de HPV em todo o país devido aos seus efeitos adversos. É mostrado, também, o Procurador da República responsável por esta requisição, alegando que não há estudos no Brasil que comprovem a eficácia desta vacina, somente estudos realizados pelo 


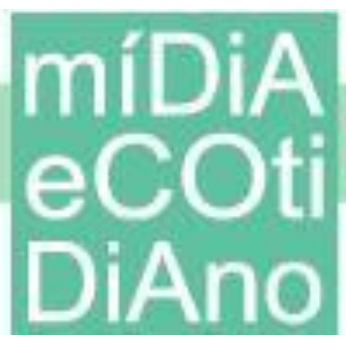

laboratório que a produz. Embora este vídeo apresente casos isolados de reações da vacina HPV e sem comprovação científica, a argumentação contra a vacina apresentada por profissionais, como médico e procurador, oferece maior credibilidade ao vídeo podendo, portanto, persuadir maior número de pessoas. Esta notícia foi, inclusive, divulgada em outras mídias sociais como WhatsApp e surgiu a partir do pedido do MPF para proibição da vacina de HPV em 2015, pedido este que foi negado em seguida pela Justiça Federal. Para combater estas e outras notícias falsas que circulam no WhatsApp o Ministério da Saúde criou o canal "Saúde sem Fake News". Este trouxe este tema, informando que a proibição da vacina nunca ocorreu e que essa vacina é segura, eficaz, e possui registro na Agência Nacional de Vigilância Sanitária (Anvisa) e que como qualquer medicamento pode causar eventos adversos, embora estes sejam raros (Ministério da Saúde, 2018). Além disso, não há evidências na literatura científica que relacione esta vacina a graves efeitos adversos e a Organização Mundial da Saúde (OMS) reafirmou a sua segurança em um documento em 2017 (WHO, 2017).

\section{Discussão}

Os levantamentos realizados sobre o movimento antivacinação na plataforma do YouTube em dois momentos diferentes mostrou que este assunto suscita muitas discussões e desperta muito interesse nos usuários da plataforma, o que, de alguma forma, reflete a sociedade em geral. O YouTube é uma ferramenta estratégica para divulgação e alcance a conteúdo diverso por estar disponível gratuitamente e ser de fácil acesso. As análises feitas nesse trabalho mostram o número crescente de publicações de vídeos sobre o movimento antivacina nos últimos anos. Apesar de existirem outros sites de compartilhamento de vídeos, o YouTube é, atualmente, o mais difundido entre os usuários de internet, consequentemente, o mais influenciador. Sua criação foi no ano de 2005 e, desde então, tem possibilitado o acesso a vídeos e também permitido que os usuários se tornem "geradores de conteúdo" (REALE; MARTYNIUK, 2016). De acordo com as estatísticas do próprio site, o YouTube possui mais de um bilhão de usuários que, diariamente, assistem bilhões de horas de vídeos e compartilham cerca de 60 horas de conteúdo por minuto (YOUTUBE, 2018). 
Nosso estudo constatou que a maioria das pessoas que publicaram vídeos no YouTube sobre esse assunto foi contra o movimento antivacina e este número tendeu para um aumento, como evidenciado na segunda etapa da pesquisa. Grande parte destes vídeos mostrou a preocupação de profissionais de saúde com a disseminação de notícias falsas sobre as vacinas e a volta de doenças que estavam controladas ou até mesmo erradicadas. Tendo em vista o grande número de vídeos postados na plataforma, é interessante também conhecer aqueles que permanecem como mais relevantes ao longo do tempo, que possuem potencial de influenciar mais pessoas e, neste sentido, foi possível identificar que 7 vídeos contra o movimento antivacinação, que apareceram na primeira etapa da pesquisa, continuaram entre os mais relevantes, mostrando que eles ainda têm forte influência nesta plataforma. Estes vídeos, de forma geral, explicam o que é a vacina e expõem as inúmeras doenças que já foram controladas por meio delas, enaltecendo sua importância para a saúde pública. Estes vídeos também falam sobre como o movimento surgiu e como ele vem se fortalecendo nos últimos anos, além de refutar os argumentos utilizados por pessoas contrárias à vacinação.

Nos vídeos neutros que permaneceram entre os mais relevantes, em sua maioria o apresentador ou mediador expõe as causas da existência do movimento antivacina, sua recente disseminação e os argumentos utilizados por pessoas adeptas e entrevistam especialistas da área de saúde para discutir estes aspectos. Todos estes profissionais são contra o movimento e explicam, utilizando evidências científicas, a importância da vacina na saúde pública. Em apenas um desses vídeos: "Domingo Espetacular conversa com pais que decidiram não vacinar os filhos", o qual mantém uma média de acesso relativamente alta (109 visualizações por dia), há entrevistas com pais que optaram por não vacinar seus filhos. Estas pessoas preferiram ter sua identidade não revelada por medo de represálias. Elas argumentam que não acreditam no efeito preventivo da vacina e dizem ter receio de seus componentes e dos efeitos adversos. Também relatam que fazem uso de outras formas de prevenção como manter uma boa alimentação, o uso de florais e homeopatia.

Embora em menor número que os vídeos contra o movimento, as postagens de vídeos “A favor" também persistem no Youtube. Nestes é possível identificar diversas fake news, que, de acordo com Allcott e Gentzkow (2017), são notícias falsas intencionalmente veiculadas para enganar os leitores sob interesse financeiro ou 


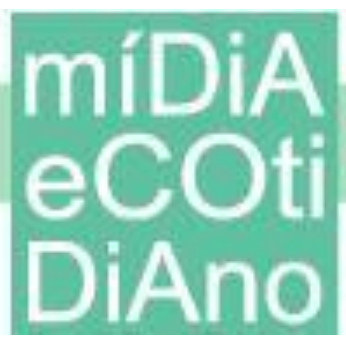

ideológico. No caso destes vídeos, a utilização de fake news possui caráter ideológico, a fim de convencer pessoas a aderirem o movimento. Além disso, esses vídeos trazem argumentos contendo desinformação, possuindo, então, uma taxa de visualização preocupante, como no caso do vídeo "Antivacina na conversa com Bial/ Por que a Globo quer que você se vacine?" que tem uma média de 681 visualizações por dia. Além das visualizações, a influência destes vídeos pode ser dimensionada pela grande quantidade de comentários escritos pelos espectadores, chegando ao número de 350 no vídeo "Meu corpo, minhas regras" e, ao analisar o conteúdo destes comentários, nota-se que a maioria das pessoas é convencida pelos argumentos apresentados nos vídeos e ainda acrescentam mais motivos para não se vacinarem.

Um fato intrigante foi do vídeo a favor que apareceu entre os mais relevantes, mas que, na verdade, é uma postagem de um outro canal maior, onde teve muito mais visualizações e curtidas, porém o YouTube não mostrou este dado na pesquisa realizada. O YouTube, com exceção de alguns conteúdos proibidos, não controla os vídeos publicados, tampouco sua veracidade e qualidade das informações. Entretanto, há outras ferramentas que ele pode utilizar para limitar os acessos a determinados vídeos. Em janeiro de 2019 o YouTube anunciou que iria desmonetizar vídeos contra a vacinação e, de acordo com uma resposta à BBC News Brasil, vídeos que digam diretamente "você não deve se vacinar" seriam retirados do ar. A empresa também informou que reduziria as recomendações de vídeos antivacina (GRAGNANI, 2019).

Estes resultados mostram que, apesar do esforço contínuo dos profissionais da área da saúde e da mídia no sentido de divulgarem informações corretas e mostrar os malefícios do movimento antivacina, há ainda muitos adeptos à antivacinação, isto é, que preferem evitar a imunização. Suas alegações são baseadas em motivos religiosos, filosóficos, como a utilização da expressão “o corpo é meu, a decisão é minha”, e também por medo dos efeitos adversos ou casos de morte que associam às vacinas, sem que haja comprovação científica confiável (FEIJÓ; SÁFADI, 2006; SARASOHN-KAHN, 2008; CDC, 2011; FOX, 2011; KATA, 2012; WANG, et al., 2015; REALE; MARTYNIUK, 2016; GUIMARÃES, 2017; SIQUEIRA et al., 2017; BBC NEWS, 2018).

As quedas na cobertura vacinal em todo o mundo, assim como o retorno de doenças consideradas erradicadas, têm sido atribuídas ao crescimento do movimento 


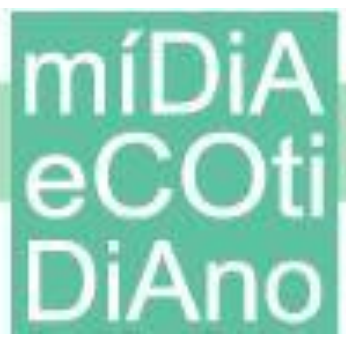

antivacina. No Brasil, segundo o Datasus, em 2005, 11 dos 26 estados tinham cobertura vacinal acima de 90\%. No entanto, em 2015 somente 5 estados mantiveram estes números. Além disso, a imunização contra sarampo, caxumba, rubéola e varicela, obtida pela vacina da tríplice e tetra viral, tiveram uma queda com o passar dos anos, apresentando uma cobertura vacinal de 100 a $120 \%$ entre os anos de 2003 e 2012, caindo para 60\% após esse ano (dados do Datasus 2016) (FEIJÓ; SÁFADI, 2006; CDC, 2011; WANG, et al., 2015; GUIMARÃES, 2017; SIQUEIRA et al., 2017; BBC NEWS, 2018). Concomitante a isso, por coincidência (ou não), o sarampo, que era uma doença considerada como erradicada no Brasil desde 2016, mostrou-se novamente presente com o registro de 995 casos no país (sendo 611 no Amazonas e 384 em Roraima), segundo a Organização Mundial da Saúde (OMS). Os casos estão sob investigação de possível importação da Venezuela, já que em abril deste ano a OMS notificou um possível surto neste país. Dentre esses casos, houve a confirmação de três mortes por essa doença (FEIJÓ; SÁFADI, 2006).

Também há um alto risco de retorno da poliomielite em pelo menos 312 cidades brasileiras. Esta doença foi a responsável por milhares de casos de paralisia infantil e também havia sido considerada como erradicada no continente desde 1994. Estas informações colocaram a OMS e o Ministério da Saúde em alerta, já que a erradicação só será possível com a vacinação em massa, mas esta pode ser ameaçada caso a cobertura vacinal sofra ainda mais quedas (FEIJÓ; SÁFADI, 2006; CDC, 2011; WANG, et al., 2015; GUIMARÃES, 2017; SIQUEIRA et al., 2017; BBC NEWS, 2018). Recentemente, os países do Mercosul fizeram um acordo para evitar a reintrodução de doenças já erradicadas na região das Américas, incluindo o sarampo, a poliomielite e a rubéola, sendo o Brasil, Argentina, Uruguai, Paraguai e Chile os países que se comprometeram a reforçar a implementação de ações de saúde nas suas fronteiras e a fornecer assistência aos imigrantes numa tentativa de manter baixa a transmissão das doenças (LABOISSIÈRE, 2018). A maioria dos profissionais de saúde relatou nos vídeos analisados suas opiniões como sendo contra o movimento antivacina, pois cientificamente compreendem a importância da utilização das vacinas como forma de prevenção de doenças. 
Keelan et al. (2007) avaliou vídeos no YouTube usando as palavras-chaves "Vaccination and imunization" e em uma época diferente e em língua diferente do nosso estudo encontrou também mais vídeos que eram positivos em relação à vacinação (a sua segurança e benefícios). Dos 153 vídeos encontrados, 79 eram positivos, 43 negativos e 31 ambíguos. Observou também que os vídeos positivos estavam de acordo com a literatura científica sobre o tema enquanto os vídeos negativos contradiziam as evidências científicas e, por fim, destacou a importância dos profissionais de saúde estarem atentos aos vídeos compartilhados em mídias sociais e preparados para responder as dúvidas de pacientes que usam estas fontes para busca de informação, e até mesmo considerar o uso destes canais para comunicação em saúde.

Apesar da maioria dos vídeos encontrados em nosso estudo no YouTube serem contra o movimento antivacina, ainda assim, é importante comentar que 15,4\% dos vídeos foram a favor e estes tiveram uma média de 7079 visualizações e 595 curtidas por vídeo, mostrando que uma parcela grande de seguidores está aderindo ou pelo menos se identificando com esta corrente de ideias. Este fato é preocupante, tendo em vista o perfil do movimento antivacina atual que é formado não somente por pessoas desinformadas ou com baixa escolaridade, mas também por pessoas com maior grau de instrução, mas que estão tendo acesso a informações sem evidências científicas, disponíveis na internet em fontes não confiáveis (FEIJÓ; SÁFADI, 2006). Por isso, se faz importante a divulgação científica por profissionais de saúde, cientistas e jornalistas que podem transmitir conteúdos confiáveis e esclarecer dúvidas acerca deste tema, como já presenciado nos vídeos disponíveis contra o movimento. Em tempos em que as pessoas têm acesso livre a grande quantidade de informação, sem que isso signifique qualidade, é importante estimular estudos que analisem conteúdos em saúde disponíveis na internet e também que se divulguem os resultados para alertar a população, já que informações incorretas e fake news nesta área podem colocar a saúde da população em risco.

\section{Referências}

ALlCOTT, H.; GENTZKOW, M. Social Media and Fake News in The 2016 Election. J Econ

Perspect, v.31, n.2, p. 211-236, 2017. 
ALMEIDA, M. I. S.; COELHO, R. L. F.; CAMILO-JUNIOR, C. G.; GODOY, R. M. F. Quem Lidera sua Opinião? Influência dos Formadores de Opinião Digitais no Engajamento. Rev Adm Contemp, v.22, n.1, p. 115-137, 2018.

BAUMAN, Z. Modernidade líquida. Rio de Janeiro: Zahar, 2001.

BBC News. Sarampo, pólio, difteria e rubéola voltam a ameaçar após erradicação no Brasil. 7 de julho de 2018. Disponível em: <https://g1.globo.com/bemestar/noticia/sarampo-poliodifteria-e-rubeola-voltam-a-ameacar-apos-erradicacao-no-brasil.ghtml>. Acesso em: 10 jul. 2018.

CDC (Centers for Disease Control and Prevention). A CDC framework for preventing infectious diseases: Sustaining the Essentials and Innovating for the Future. Georgia, 2011.

DOBSON, R. Media misled the public over the MMR vaccine, study says. BMJ, v. 326, n. 7399, p. 1107, 2003.

DYER, O. Wakefield tells GMC he was motivated by concern for autistic children. BMJ, v. 336, n. 7647, p. 737-743, 2008.

FEIJÓ, R. B.; SÁFADI, M. A. Immunizations: three centuries of success and ongoing challenges. J Pediatr, v. 82, n. 3, p. S1-S3, 2006.

FOX, S. Health topics: $80 \%$ of internet users look for health information online, Pew Internet \& American Life Project. 1 de fevereiro de 2011. Disponível em:

$<$ https://www.issuelab.org/resources/9648/9648.pdf>. Acesso em: 30 jun. 2018.

GRAGNANI, J. Rede antivacina no Brasil importa teorias da conspiração dos EUA e cresce com sistema de recomendação do YouTube. BBC News Brasil. 20 de junho de 2019.

Disponível em: <https://www.bbc.com/portuguese/brasil-48695113>. Acesso em: 07 set. 2019.

GUIMARÃES, K. Vacinação em queda no Brasil preocupa autoridades por risco de surtos e epidemias de doenças fatais. BBC Brasil, 29 de agosto de 2017. Disponível em: <https://www.bbc.com/portuguese/brasil-41045273>. Acesso em: 24 jun. 2018.

KARAFILLAKIS, E.; DINCA, I.; APFEL, F.; CECCONI, S.; WURZ, A.; TAKACS, J. Vaccine hesitancy among healthcare workers in Europe: a qualitative Study. Vaccine, v. 34, n. 41 , p. 5013-5020, 2016.

KATA, A. Anti-vaccine activists, Web 2.0, and the post-modern paradigm - An overview of tactics and tropes used online by the anti-vaccination movement. Vaccine, v. 30, p. 3778- 3789, 2012.

KEELAN, J.; GARCIA, V. P.; TOMLINSON, G.; WILSON, K. YouTube as a Source of Information on Immunization: A Content Analysis. JAMA, v. 298, n. 21, p. 2482-2484, 2007.

KUMAR, V.; GUPTA, S. Conceptualizing the evolution and future of advertising. J Advert, v. 45, n. 3, p. 302-317, 2016.

LABOISSIÈRE P. Agência Brasil: Doenças erradicadas voltam a assustar - desafios da vacinação. 3 de julho de 2018. Disponível em: 
$<$ http://agenciabrasil.ebc.com.br/saude/noticia/2018-07/doencas-erradicadas-voltam-assustarveja-os-desafios-da-vacinacao>. Acesso em: 20 ago. 2018.

LEITE, L. R. T.; MATOS, J. C. M. Zumbificação da informação: A desinformação e o caos informacional. Revista Brasileira de Biblioteconomia e Documentação. v. 13, n. esp CBBD, p. 2334-2349, 2017.

LYOTARD, J. F. A condição pós-moderna. 8. ed. Rio de Janeiro: J. Olympio, 2004.

MINISTÉRIO DA SAÚDE. Saúde sem Fake News. 28 de agosto de 2018. Disponível em: <https://saude.gov.br/fakenews/44143-mpf-proibe-vacina-contra-hpv-fake-news >. Acesso em: 15 fev. 2020.

MIZUTA, A. H.; SUCCIA, G. M.; MONTALLIA, V. A. M.; SUCCIA, R. C. M. Perceptions on the importance of vaccination and vaccine refusal in a medical school. Ver Paul Pedriatr, v. 37, n. 1, 2018.

MORETTI, F. A.; ELIAS DE OLIVEIRA, V. E.; DA SILVA, E. M. K. Acesso a informações de saúde na internet: Uma questão de saúde pública? Rev Assoc Med Bras, v.58, n. 6, p. 650$658,2012$.

OPAS BRASIL. Casos de sarampo estão aumentando em todo o mundo devido a lacunas na cobertura vacinal, indica novo relatório da OMS. 29 de novembro de 2018. Disponível em: $<$ https://www.paho.org/bra/index.php?option=com_content\&view=article\&id=5811:casosde-sarampo-estao-aumentando-em-todo-o-mundo-devido-a-lacunas-na-cobertura-vacinalindica-novo-relatorio-da-oms\&Itemid=812>. Acesso em: 25 set. 2019.

REALE, M. V.; MARTYNIUK, V. L. Divulgação Científica no Youtube: a construção de sentido de pesquisadores nerds comunicando ciência. In: CONGRESSO BRASILEIRO DE CIÊNCIAS DA COMUNICAÇÃO, 39, 2016, São Paulo. Anais... São Paulo: Intercom, 2016. Disponível em: <http://portalintercom.org.br/anais/nacional2016/resumos/R11-0897-1.pdf>. Acesso em: 12 set. 2019.

SARASOHN-KAHN, J. The wisdom of patients: health care meets online social media. California Health care Foundation, 2008. Disponível em:

<https://www.issuelab.org/resources/11675/11675.pdf>. Acesso em: 1 jul. 2018.

SIQUEIRA, L. G.; MARTINS, A. M. E. B. L.; VERSIANI, C. M. C.; ALMEIDA, L. A. V.; OLIVEIRA, C. S.; NASCIMENTO, J. E.; ALECRIM, B. P. A.; BEZERRA, R. C. Assessment of the organization and operation of vaccine rooms in primary health care in Montes Claros, Minas Gerais, Brazil, 2015. Epidemiol Serv Saúde, v. 26, n. 3, p. 557-568, 2017.

VASCONCELLOS-SILVA, P. R.; CASTIEL, L. D.; GRIEP, R. H. A sociedade de risco midiatizada, o movimento antivacinação e o risco do autismo. Cienc Saúde Colet, v. 20, n. 2, p. 607-616, 2015.

WANG, E.; BARAS, Y.; BUTTENHEIM, A. M. Everybody just wants to do what's best for their child: Understanding how pro-vaccine parents can support a culture of vaccine hesitancy. Vaccine, v. 33, p. 6703-6709, 2015. 
WORLD HEALTH ORGANIZATION, WHO. Human papillomavirus vaccines: WHO position paper. Weekly Epidemiological Record, v. 92, n. 19, p. 241-268, 2017.

YOUTUBE. Plataforma digital do Youtube: Estatísticas para imprensa. Disponível em: <https://www.youtube.com/intl/pt-BR/yt/about/press/>. Acesso em: 6 jul. 2018. 